\title{
Blackies datter
}

\author{
Medisinske fag ramler ikke ned fra månen, de formes av enkeltmennesker og organisasjoner, \\ ofte gjennom lange kamper. Anna Stavdal har i to tiår vært en lederskikkelse blant norske, \\ nordiske og europeiske allmennleger. Hun kjemper for en fagsterk og selvkritisk allmenn- \\ medisin med en yrkespraksis i pakt med idealene. Hva driver henne?
}

Anna Stavdal venter på meg mellom gamle tuntrær foran barndomshjemmet i Asker. Hun er høy og rank, med oppmerksomme øyne.

- Jeg går i sort i dag, til ære for deg.

Vi går inn. Det er lunt og luftig i Annas rom. «She's the most elegant woman I know,» skriver tidligere president i The Royal College of General Practitioners, norgesvennen Iona Heath. «An extraordinary combination of warmth, intellect, grace and style. And I think she is more easily hurt than many might assume.»

\section{Uskyldig eksentrisk}

- Jeg vokste opp på et relativt stort lerret. Du må vite litt om bakgrunnen min, for den lever gjennom meg. Her i Asker bodde jeg med mor, far og storesøster. De var ikke helt vanlige, men det visste jeg ikke da. Barn tror jo at det som skjer i deres liv er det normale. Far drakk med Aksel Sandemose og Inger Hagerup, morfar med Arne og Hulda Garborg. Erik Bye var nærmeste nabo, hans datter Anne er fortsatt min nære venn. Det er en gave å ha hatt norsk kulturhistorie innflettet $\mathrm{i}$ den personlige historien. Men det er også et mørke der. At far drakk med store kunstnere, betyr også at han drakk, kort og godt. Han sluttet da han var 41 år, det var kanskje hans største bragd. Men han ble ikke dermed kvitt demonene sine. Han var følsom, hadde et veldig temperament. Han sto meg veldig nær, og jeg ble nok invadert av hans liv mer enn godt var.

Hun viser meg bronsebysten av faren, et vakkert mannshode med stort, bølgende hår.

Annas mor var Berit Stavdal, damen som hadde morgengymnastikken på NRK radio. Vi husker stemmen hennes: «Og strekk ut!» Berit var utdannet skuespiller og filolog, hun underviste på Oslo katedralskole gjennom mange tiår. Hun dro ungene inn i kunsten, i Suttungbevegelsen og leikarring, hun bar familien og økonomien.

Villaen i skogen ble farens borg og skjulested. Fredrik Stavdal, kalt «Blackie», fikk beina slått under seg av sekstiåtterbølgen ved Universitetet i Oslo. Han var Norges første magister i sosiologi, hadde røtter i amerikansk akademisk tradisjon og likte å kalle europeiske forskningstradisjoner for «synsing». Som motstandsmann under krigen og deltaker i Mot Dag-miljøet fnøs han av de unge nyfrelste marxist-leninistene og deres liksomsosialisme. Slik fikk Blackie en ny krig, på Blindern. Utskjelt som reaksjonær positivist trakk han seg tilbake. Huset i Asker ble hans refugium, et selvvalgt akademisk isolat med to døtre som lydhørt hjemmepublikum for høye idealer og sviende samtidskritikk.

- Jeg er vokst opp som en protestant, og da mener jeg ikke i religiøs forstand. Familiekulturen var eksentrisk, med kryssende strømmer av overlegenhet og selvforakt som jeg ikke forsto da. Jeg hadde ikke annet sik-

\section{«Det er merkelig naivt à tro at man ikke påvirkes av penger og smiger»}

kerhetsnett enn mitt eget hode. Sånn sett var det interessant å komme inn i medisinen, det liknet ikke på noe fra hjemmet. Anatomi og fysiologi var rimelig ukomplisert!

\section{Gjennomføreren}

«Hun kan være nøktern som få, men egentlig er hun en vulkan! At hun ble lege, var akkurat som ventet,» sier barndomsvenninnen Anne Eriksdatter Bye. «Vi lekte doktor fra vi var småjenter. Ikke at Anna var spesielt empatisk, men for et organisasjonstalent! Hun hadde sin første jobb da hun var ni år - som redaksjonssekretær i bladet Nå og da, det kom ut nå og da. Jeg var to år eldre og redaktør. Anna har alltid vært en som gjør det hun tenker hun burde gjøre. Hun tar den telefonen, skriver det brevet, tar den reisen. Hun gjennomfører. Hun er ikke sta, men heller ikke myk og smidig. Det er ikke alltid lett å være Anna, men det er ofte morsomt!»

Anna Stavdal har en uvanlig evne til å gjøre mange ting samtidig, sies det. Mens hun forteller om oppveksten med Blackie og Berit, oppstår en treretters gourmetmiddag mellom hendene hennes. Salat med varm paté og bringebær, innbakt flyndre i ovnen. God vin i glasset, et vakkert kjøkken, vertinnen med lyse krøller mot det mørke. Så perfekt. Nei, hun har glemt kantarellene. Blikket er innadvendt, hun tenker, søker ord, prøver å få meg til å forstå noe viktig. Kantareller er ikke viktig.

\section{Organisasjonsmennesket}

- Hjemme lærte jeg at man må se på seg selv som et instrument og finne ut hvor man kan ha noe å utrette, sier Anna. - Jeg har vært frontfigur i mange sammenhenger fordi jeg vil bidra, få ting til å skje. Jeg har stukket meg frem, jeg er blitt kritisert og angrepet, og jeg tåler det. Men når kolleger har søkt verv og posisjoner av åpenbar forfengelighet med dertil hørende overdreven kompromissvilje, har jeg følt meg sveket, sier hun.

- Som nyutdannet var jeg vikar i allmennpraksis. Jeg forsto at faget var i støpeskjeen på mange vis, men de unge legene var ikke på banen. Jeg spurte min daværende sjef Sverre Lundevall om NSAM (Norsk selskap for allmennmedisin) var en «losje» forbeholdt gamle ml-ere av hankjønn. Sverre, selv gammel ml-er, foreslo meg til NSAM-styret i 1993. NSAM ble grunnlagt 1981 etter mal av internasjonale colleger, med vekt på faglige idealer og standarder, atskilt fra fagforeningssaker. Fra 1999 til 2003 var jeg leder. Det er jeg stolt av, jeg har dyp respekt for de kloke allmennmedisinske kollegene jeg fikk lov til å representere.

\section{Resultater}

- Hva fikk du utrettet i din tid i NSAM?

- Tre saker tenker jeg på med særlig glede. Den ene er at vi etter seig kamp fikk et regelverk som holder legemiddelindustrien på armlengdes avstand. Noen ville helst beholde industripengene, gratismiddagene og smøreturene til Paris og Roma. Og mange stusset da fattige NSAM insisterte på å betale reise og opphold for legemiddelrepresentantene som skulle informere oss om ny diabetesbehandling. Men i dag erkjenner de fleste at gylne bånd til de kommersielle aktørene ødelegger troverdigheten som legene er avhengige av. Folk 


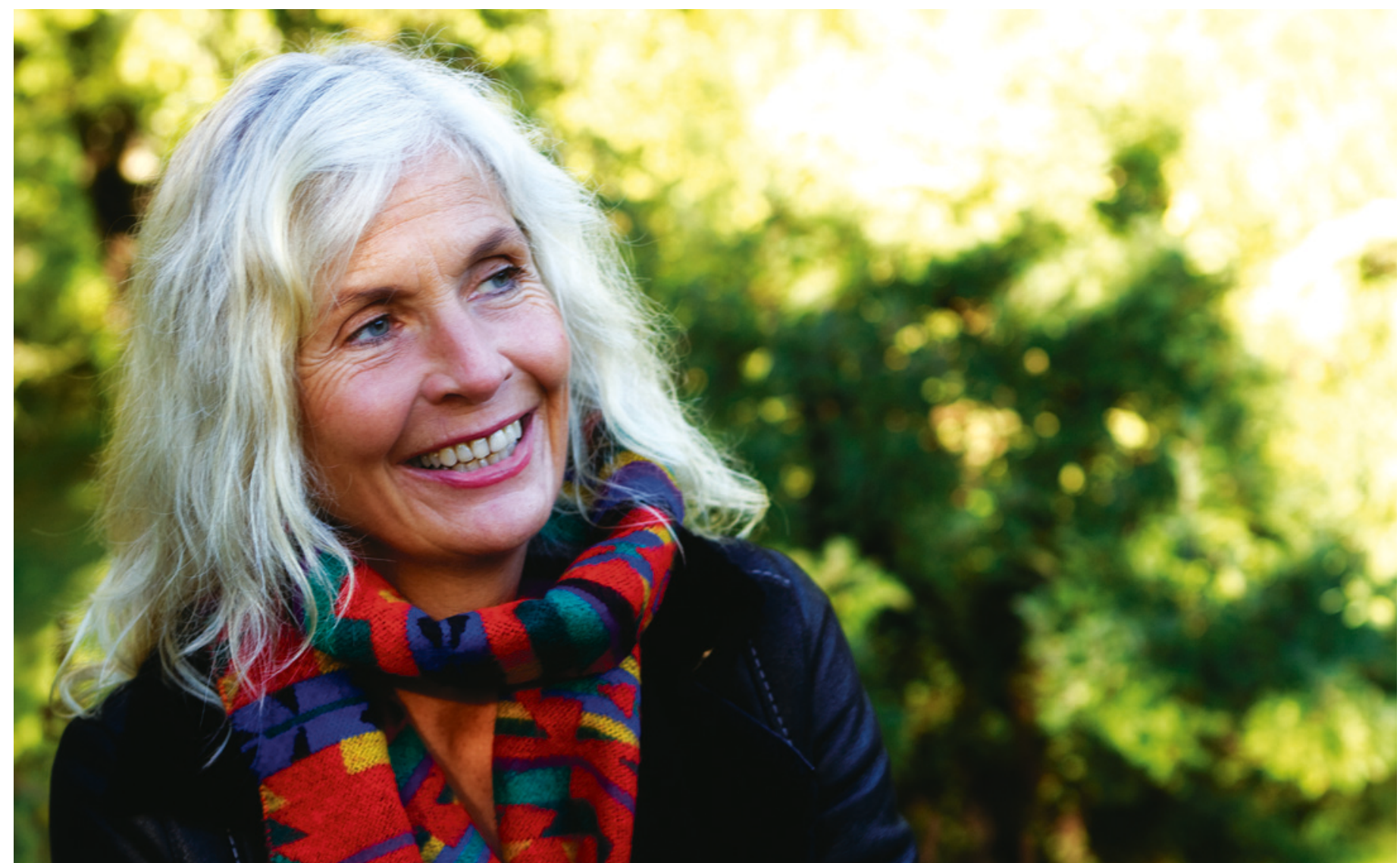

Foto: Einar Nilsen

\section{Anna Stavdal}

Født i Oslo i 1959

- Cand.med. Universitetet i Oslo 1987

- Spesialist i allmennmedisin, Bolteløkka legesenter i Oslo

- Universitetslektor ved Universitetet i Oslo

- Veileder i allmennmedisin

- Fast ukentlig spaltist som «VGs fastlege» 2002-08

- Leder av NSAM 1999-2003

- Leder av Stiftelsen SJPHC fra 2001 og president for Nordic Federation of General Practice 2005-11

- Visepresident i WONCA Europe flest har gode antenner for grådighet og forfengelighet hos leger. Og det er merkelig naivt å tro at man ikke påvirkes av penger og smiger, i tankegang og faglige valg. Det varmer meg at Norge er blitt et foregangsland i dette spørsmålet.

Hun fortsetter: - Den andre saken jeg er stolt av, er etableringen av Nordic Federation of General Practice i 2005, en slagkraftig organisasjon hvor nordiske kolleger kan gjøre hverandre sterke i arbeidet for en allmennmedisin som har integritet og kraft.

Det tredje står kanskje mitt hjerte aller nærmest. Det er tydeliggjøringen av allmennmedisinens kjerneverdier og mål gjennom plakaten Sju teser for allmennmedisin fra 2001 (1). Faget vårt skal ha en forankring i kunnskap om levd liv og hjelperrollen. Vi er ikke «sykehusmedisin light». Allmennmedisinen er annerledes. Det handler om diagnostikk og behandling, men enda mer om hva sykdom og medisinsk hjelp betyr i et liv. Primærmedisinen har et unikt mandat, og allmennleger må forstå at rollen som fastlege er en ganske annen enn sykehuslegenes.

\section{Det indre kompasset}

- Hva trenger nye allmennleger i verktøyskrinet for å fungere godt?

- De må ha trygghet på å kunne skille sykt fra friskt. Hva er normalt, og hvor sne- vert skal det defineres - hvor mange skal stemmes ut som avvikere? Presset fra de friske øker. De må tas på alvor og hjelpes til trygghet, ikke til flest mulig helsetjenester. Det krever ryggrad, faglig sikkerhet og profesjonelle samtaleferdigheter, hevder hun.

- Jeg synes universitetene i for liten grad gir studentene et indre kompass som de kan bruke til å finne retning når livet og faget floker seg til, slik det alltid gjør. Det indre kompasset er å kunne utfordre sine vurderinger og tanker - å kunne være selvkritisk uten å miste motet. Det er for lite intellektuell dannelse i studiet og for lite kontakt mellom studenter og leger. Man belønner og etterspør faktaoppgulp, ikke mot og nysgjerrighet. Slikt gjør unge leger usikre, og derfor trenger vi bedre systemer for veiledning av yngre kolleger.

\section{Mer paternalisme!}

- Jeg er tilhenger av mer paternalisme i legerollen. Misforstått pasientsentrerthet kan bli kelnermedisin hvor pasienten får det hun ber om selv om det ikke gagner henne«ja selvsagt skal du få sykmelding og et nytt MR». Behovet for å bli likt kan gjøre at vi hjelper de minst syke til å misbruke systemet. Vi må våge å sette foten ned, bruke fagkunnskap og psykologisk teft til å påvirke folk, bygge tillit. Alle må tåle 
usikkerheten som hører livet til, sier allmennmedisinspesialisten.

- Å hjelpe pasienter uten å lede er umulig. Leger har makt og skal ha det. Derfor må vi også ha strenghet og selvrefleksjon i legeyrket. Selvjustis og grenser er nødvendig for å bevare åpenheten og en tjenende innstilling. Arroganse blant leger er mer enn en klisjé. Ofte handler det om utrygghet. For å unngå det trenger vi gode systemer for veiledning av de unge. Det er berikende, i mester-svennforhold vil også veilederen utvikle seg.

\section{Mislykket byråkrat}

I 2010 sa Anna ja til en bistilling som seniorrådgiver i Statens helsetilsyn. - Jeg tenkte det var viktig å fremme et allmennmedisinsk perspektiv hos tilsynsmyndigheten.

I vurderinger av klagesaker møtte hun snart motstand fra tilsynskolleger med sykehusbakgrunn.

Kollega Svein Zander Bratland forteller: «Allmennleger arbeider og tenker i et paradigme som en del sykehusleger ikke forstår og ikke anerkjenner verdien av. Å møte befolkningens usorterte helseplager og krav uten å medikalisere selve livet og uten å sprenge alle rammer i helsevesenet, det krever breddekunnskap og mot til å ta en kalkulert risiko. Allmennlegen skal skille farlig fra ufarlig på alle medisinens områder. Selvsagt må det skje feil og uhell. Anna frontet disse innsiktene med sin faglige tyngde, men fikk lite gehør. Jeg forstår at det intellektuelt og følelsesmessig ble uholdbart for en lege med faglig stolthet. At hun sluttet, var et tap. Jeg håper hun en dag søker en lederjobb i Helsetilsynet.»

\section{Penger og akademiske idealer}

- Jeg mener at vi burde hatt en faglig allmennlegeforening utenfor Den norske legeforening, en som kunne virkeliggjøre idealene om kritisk nysgjerrighet og uselvisk saklighet uten å bli mistenkt for å ha en pengeinteresse på lur i argumentasjonen. Der burde vi diskutere medikalisering, politisk uvitenhet, risikohysteri og mangelfull egenomsorg - ikke høringsnotater og kronebeløp i taksthefter!

Og fortsetter: - Så mener jeg at akademikerne i norsk allmennmedisin står i fare for å svikte de akademiske idealene. Hvor holdes nytenkning og kritisk refleksjon $i$ hevd? Hvor kjempes det på barrikadene? I altfor liten grad ved universitetene, det kan se ut til at professorene går i takt med myndigheter og opinion for å få kroner til sine egne forskningsprosjekter. Det er misbruk av makt ikke å bruke den.

\section{Klinikeren}

Anna Stavdal er fastlege i Oslo. Hun har to engasjementer i tillegg til de avtalefestede.
- Siden starten for 15 år siden har jeg vært lege for kvinner som søker ly på Nattergalen, en avdeling under natthjemmet for prostituerte. Det er fire plasser. Brukerne har ikke «boevne», som det heter, de har erfaring fra prostitusjon, rus og psykiatri. De som jobber der, investerer mye av seg selv, de er livreddere. Inntil kvinnene dør, for det gjør de jo. Arbeidet krever improvisasjon, mot og kompromisser. Det er et privilegium å kunne bruke legeautoriteten og lykkes en gang iblant med å skaffe hjelp til de aller mest sårbare.

Annas andre bijobb er på Mariahuset, en katolsk stiftelse hvor tre psykisk utviklingshemmede kvinner har bodd i over 30 år. - Jeg er takknemlig for å ha en rolle der, i en sammenheng hvor man fortsatt praktiserer «tjeneste for andre» som et opphøyet livsvalg.

\section{Høye hæler og dyr vin?}

Fra Nattergalen og Mariahuset er det et drøyt steinkast til WONCA, verdensorganisasjonen for allmennmedisin. Der har Anna Stavdal vært visepresident for Europa siden 2010

- WONCA er en stor organisasjon. Er det pampelivet som frister, med gode betingelser, høye hæler og champagne?

Anna smiler. - Tja. I og med at WONCA samler folk fra mange land kan man finne veldig forskjellige skikker og motiver blant representantene. Som skandinav fremstår jeg nok som økonomisk nøktern, idealist og feminist, sier hun.

- Innstillingen til privatøkonomi og samkvem med legemiddelindustrien spriker mye i organisasjonen. Selv har jeg alltid gått økonomisk underskudd i mine tillitsverv, praksiskompensasjon for faglig arbeid var ikke aktuelt i NSAM eller i Nordic Federation. I WONCA gis det heller ikke dekning for inntektstapet de dagene jeg er borte fra praksisen. Jeg synes faktisk det er bra at organisasjoner drives av mennesker som ikke søker frynsegoder og penger. Det dreier seg om å løse vanskelige oppgaver, man trenger folk som har glede av å få noe til, at det er selve belønningen.

\section{Kan WONCA forandre verden?}

- Hva skal vi med disse organisasjonene, Anna? Blir det ikke mange tomme ord på gebrokkent engelsk i kjedelige møterom? Dette har du brukt tid og krefter på i over 20 år. Tror du virkelig at du forandrer verden?

- Takk for at du spør. Svaret er ja. Omtrent som politiske partier kan vi skape endring og bygge nye strukturer i verden. Det kan virke langdrygt og ineffektivt sett utenfra og på kort sikt. Men vi har makt, WONCA Europe representerer nærmere 100000 leger fra 49 land, forteller hun.

- Over tid former vi virkeligheten ved å sette dagsorden, ved å skape arenaer hvor uenighet kan håndteres, erfaringer deles, dilemmaer drøftes og ideer oppstå. Mange store saker er håpløse å gjøre noe med hvis man ikke kan drive lobbyvirksomhet med en viss tyngde, hevder hun.

- Et gjennomarbeidet forslag på vegne av Europas allmennleger slår hardere enn Annas private synsing, selv om standpunktet er det samme. For eksempel prøver vi å legge press på EU for at de skal endre direktivene og lage bedre kravspesifikasjoner til spesialiteten i allmennmedisin på tvers av landegrenser. I andre saker henvender vi oss direkte til helseministrene i flere land. Eller vi påvirker universiteter til å endre legeutdanningen, ved å dokumentere at kompetent primærhelsetjeneste gir bedre helse for en lavere kostnad.

Jeg har spurt meg selv hvorfor dette er så rikt for meg. Det handler om å dele - jeg tror faktisk det tangerer noe så stort som kjærlighet. Kjærlighet til mennesker, til det gode, til overbærenhet og forsoning. Å dele er å øke sin egen rikdom som medmenneske.

\section{Et pusterom fra jante}

- Blir du verdsatt i WONCA med all denne idealismen?

$-\mathrm{Ja}$, det tror jeg. Iblant føler jeg meg tryggere i den internasjonale potpurrien enn i norske sammenhenger. I WONCA tror de det er «typisk norsk» når det kanskje er «typisk Anna». Man bedømmes annerledes av utlendinger, de vet jo ikke om man avviker fra den norske væremåten, smiler hun.

- Jeg tror de opplever at jeg i rollen som «friskt pust fra nord» løser opp i formelle og tungt mannsdominerte samværsformer. Samtidig kan jeg vise skarpe kanter i saksdiskusjonene, jeg er argumenterende og tydelig på hva jeg mener. Det kan være uvant for mange at en feminin kvinne kan opptre slik. Jeg registrerer at kjønnsrelasjonene er temmelig gammeldagse, med menn og kvinner mer åpenbart som jegere og bytte enn vi er vant til. Det er $\mathrm{OK}$, alt $\mathrm{i}$ alt blir det balanse og en fin gjensidig respekt mellom allmennleger fra mange land.

Vi setter oss i stuen. Blackies bronseansikt ser vennlig mot datteren mens hun finner frem September song på stereoanlegget. Tora Augestads stemme skinner i den høyloftede stuen. Det er kveld, tid for nattoget hjem. «Stor arv det er for mannen, av godtfolk vera fødd,» skrev Vinje. Så også for kvinnen.

\section{Edvin Schei}

edvin.schei@isf.uib.no

Tidsskriftet

\footnotetext{
Litteratur

1. Sju teser for allmennmedisin. Tidsskr Nor Lægeforen 2003: 123: 495 .
} 